\title{
On a new compound of sulphur, chlorine and oxygen
}

\section{Millon}

To cite this article: M. Millon (1850) On a new compound of sulphur, chlorine and oxygen, Philosophical Magazine Series 3, 37:252, 474-475, DOI: 10.1080/14786445008646661

To link to this article: http://dx.doi.org/10.1080/14786445008646661

曲 Published online: 30 Apr 2009.

Submit your article to this journal $\pi$

Џll Article views: 2

Q View related articles $\sqsubset$ 
water, and precipitation from it by concentrated alcohol. The aqueous solution of these crystals, treated with hydrochloric acid, deposited small crystals of an organic acid, slightly soluble in cold water. On attentively examining these crystals, M. Heintz ascertained that they were identical with succinic acid; the experiments first performed were merely qualitative, but they were afterwards completed by the elementary analysis, of a small quantity certainly, of these crystals. The form of the crystals was, moreover, that of an oblique rhombic prism; and $M$. Heintz found, by very exact admeasurement, that the angles of these crystals were equal to those of pure succinic acid. These experiments sufficiently demonstrate the interesting fact, announced by the author, relative to the existence of succinic acid in the animal oconomy.-Journ. de Pharm. et de Chim., Septembre 1850.

\section{ON A NEW COMPOUND OF SULPHUR, CHLORINE AND OXYGEN.} BY M. MILLON.

To prepare this, fill a bottle of the capacity of 4 to 5 litres with moist chlorine, and introduce at first 20 to 30 grms. of chloride of sulphur saturated with chlorine, and then 2 or 3 grms. of water; agitate the mix ture, and surround the bottle with a freezing mixture of ice and common salt during 4 or 5 hours. A great disengagement of hydrochloric acid occurs; the bottle is to be again filled with moist chlorine and replaced in the freezing mixture, and this is to be repeated till the chloride of sulphur becomes a crystalline mass. These crystals are destroyed with violent action by water, alcohol or diluted acids. But if, after freeing them from the chloride of sulphur which renders them impure, they are allowed to fall into a very dry tube, the open end of which is closed by the lamp, these crystrals in two or three months soften, and in eight months become an extremely fluid liquid; it is an isomeric transformation which becomes evident, not only by the change of its physical qualities, but also by the alteration of its chemical properties. Thus the liquid is no longer, as when in the crystallized state, decomposed by water, with violence, alcohol or weaker acids; on the contrary, when poured into water it is quietly deposited at the bottom of the vessel in the form of an oil, which eventually changes completely into sulphuric and sulphurous acids. This transformation is entirely in agreement with its analysis, which leads to the composition of sulphur, chlorine and oxygen, $\mathrm{S}^{2} \mathrm{O}^{3} \mathrm{Cl}^{2}:-$

$$
\begin{aligned}
& \mathbf{S}^{2} \ldots \ldots \ldots \quad 400 \text { or } 25 \cdot 20 \\
& \mathrm{O}^{3} \ldots \ldots \ldots \ldots \quad 300 \quad \ldots \quad 19 \cdot 93
\end{aligned}
$$

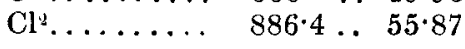

$$
\begin{aligned}
& 1586.4 \quad 100 \cdot 00
\end{aligned}
$$

The analysis is performed with the liquid modification; a weighed vessel is filled with it, and is broken in a bottle containing nitrous nitric acid. The reaction which occurs is moderated by cooling the bottle; the sulphur is subsequently estimated in the state of sulphate 
of barytes, and the chlorine in that of chloride of silver.-Journ. de Pharm. et de Chim., Août 18 ŏ0.

\section{PREPakATION AND ANALYSIS OF CODEIA. BY DR. ANDERSON.}

This alkali was obtained, as usual, from the mother-liquor from which morphia had been precipitated by ammonia. As the codeia forms only a sixteenth to a thirtieth of the morphia, it is of course mixed in this fluid with a corresponding quantity of muriate of ammonia, which must be decomposed by potash in order to obtain it. Much advantage is gained, however, by first evaporating the fluid to crystallization, and expressing the crystals deposited, as in this way the greater part of the muriate of ammonia, which is the more soluble salt of the two, is left in solution; and by repeating the crystallization many times, it may be entirely removed, and crystals obtained which are pure hydrochlorate of codeia. For the preparation of codeia, however, it would be worse than useless to carry the process thus far, as the solubility of hydrochlorate of codeia and ammonia differs so little, that much of the former salt would be lost ; but by carrying it a certain length, the greater part of the sal-ammoniac may be separated without any material loss of codeia, and the subsequent steps of the process much facilitated. The crystals so obtained being dissolved in boiling water, strong solution of caustic potash is added in excess, when codeia is in part precipitated as an oil, which by-and-by concretes into a solid mass, and is partly deposited in crystals as the solution cools. By evaporating the fluid. another crop of crystals is obtained; and finally, when the motherliquor has been concentrated to a very small bulk, it becomes filled on cooling with long silky needles of morphia, which has been retained in solution by the excess of potash. A certain quantity of morphia appears always to remain in solution along with the codeia, but its quantity seems to vary considerably. Its presence in this solution has been observed before, and it has been stated that it exists in the form of a double salt with codeia; Dr. Anderson states, however, that this is not consistent with his experience; at least the sult separated from the muriate of ammonia by successive crystallizations contained no morphia, but, as has been already stated, was pure hydrochlorate of codeia.

The crystals of codeia precipitated by potash in the manner described, are always more or less coloured. They are purified by solution in hydro hloric acid, boiling with animal charcoal, and reprecipitation with a slight excess of potash, and the precipitate ob. tained finally dissolved in æther to separate any morphia which may adhere to it. For this purpose hydrous æther is best adapted; and it ought to be free from alcohol, as if any be present, the ather evaporates and a syrupy fluid is left behind, which refuses to crystallize. When the rether is anhydrous, it dissolves the codeia with much greater difficulty; and by evaporation small crystals are deposited, which are anhydrous. 